\title{
Standardisasi Pengelolaan Laboratorium Di Lingkungan Direktorat Peninggalan Purbakala
}

\author{
Oleh \\ Ari Swastikawati, $\mathrm{S} S \mathrm{Si}, \mathrm{U}$ \\ Balai Konservasi Peninggalan Borobudur
}

\section{A. Latar Belakang}

Definisi laboratorium menurut Procter (1981) adalah tempat atau ruangan di mana para ilmuwan bekerja dengan peralatan untuk penyelidikan (penelitian) dan pengujian terhadap suatu bahan atau benda. Sedangkan menurut ISO/IEC Guide 21986 , laboratorium adalah instansi atau lembaga yang melaksanakan kalibrasi dan pengujian. Sedangkan definisi pengujian adalah kegiatan teknis yang terdiri atas penetapan, penentuan satu atau lebih sifat atau karakteristik dari suatu produk, bahan, peralatan, organisme, fenomena fisik, proses atau jasa, sesuai dengan prosedur yang telah ditetapkan. Laboratorium penguji meliputi laboratorium kimia, fisika, biologi, medis, listrik, mekanis, dan organoleptik.

Laboratorium memiliki peran vang penting dalam kegiatan konservasi dan pemugaran benda cagara budaya. Analisis laboratorium diperlukan untuk mencari data yang digunakan untuk mendukung kegiatan konservasi dan pemugaran benda cagar budaya. Analisis laboratorium dilaksanakan sebelum, selama, dan sesudah pelaksanaan kegiatan konservasi dan pemugaran. Terkait dengan salah satu tupoksi Balai Konservasi Peninggalan Borobudur, dalam melaksanakan kajian di bidang konscrvasi, teknik sipil, arsitektur, geologi, biologi, kimia dan arkeologi maka sudah scharusnya BKPB memiliki laboratorium pengujian dan laboratorium konscrvasi yang kngkap. Agar dapat membantu pelaksanaan kegiatan kajian sccara maksimal maka laboratorium
Pengujian (fisik, kimia, biologi) dan

Laboratorium Konservasi harus didukung oleh sumberdaya manusia, sarana, dan prasarana terutama peralatan yang memadai.

Berbeda dengan BP3 (Balai Pelestarian Peninggalan Purbakala) yang salah satu tupoksinya adalah melaksanakan pemeliharaan peninggalan sejarah dan purbakala baik yang bergerak maupun tidak bergerak termasuk situs-situsnya. Di mana sebelum melaksanakan pemeliharaan baik konservasi maupun pemugaran, BP3 diharuskan untuk melaksanakan kegiatan perencanaan. Perencanaan konservasi maupun pemugaran didasarkan pada hasil Studi Teknis Konservasi maupun Studi Kelayakan Pemugaran. Oleh karena itu peran dan fungsi laboratorium di lingkungan BP3 terutama mendukung kegiatan studi teknis konservasi maupun studi teknis pemugaran. Berdasarkan hasil studi teknis tersebut dapat ditentukan metode konservasi yang tepat. Sehingga cakupan kegiatan analisis yang dilakukan oleh laboratorium BP3 lebih terbatas.

Terkait dengan otonomi daerah dimana daerah dapat melaksanakan kegiatan pemugaran benda cagar budaya. Maka sekalipun cakupan kegiatan analisisnya terbatas, laboratorium BP3 juga berperan membantu daerah untuk mclakukan analisis. ()lch karena itu perlu kiranya dibuat standardisasi dalam pengelolaan laboratorium di lingkungan Direktorat Purbakala terkait dengan tupoksi masing masing I P'T tersebut.

\section{B. Maksud dan Tujuan}

Maksud tulisan ini adalah memberikan masukan bagaimana meningkatkan peran dan fungsi laboratorium dalam pelestarian benda cagar budaya khususnya di lingkungan Direktorat Peninggalan Purbakala. Sedangkan tujuannya adalah membuat standardisasi pengelolaan laboratorium di lingkungan Direktorat Peninggalan Purbakala.

\section{Standardisasi Laboratorium Di Lingkungan Direktorat Purbakala \\ D a la m rangka} meningkatkan peran dan fungsi laboratorium di lingkungan Direktorat Purbakala maka standardisasi laboratorium meliputi aspek sumberdaya manusia, analisis, dan peralatan, serta status laboratorium.

a) Standardisasi I aboratorium dari Aspek Sumberdaya Manusia

B a la i Konservas Peninggalan Borobudur sebagai pusat kajian di bidang konservasi berperan untuk menemukan metode konservasi serta bahan konservasi yang tepat. Sehingga metode serta bahan konservasi tersebut dapat digunakan sebagai acuan atau pedoman untuk penanganan benda cagar budaya seluruh di Indonesia. ()leh karena itu sumberdaya manusia yang bekerja di laboratorium $\mathrm{BK} \mathrm{PB}$ adalah

$\checkmark$ SI-Kimia (MIPA),

$\checkmark$ SI-I isika (MIPA),

$\checkmark$ SI-Biologi $(\mathrm{MIP} A)$,

$\checkmark$ Si-cicologi

$\checkmark$ D)3-Analis Kimia (MIPi)

$\checkmark$ Sild jurusan IPI 
Balai Pelestarian Peninggalan Purbakala (BP3), salah satu kegiatannya adalah melaksanakan studi teknis konservasi. Sehingga SDM yang bekerja di laboratorium BP3 dituntut dapat menentukan metode atau memilih metode dan bahan yang akan digunakan dalam kegiatan konservasi. Di mana metode dan bahan tersebut sudah dikaji sebelumnya oleh Balai Konservasi Peninggalan Borobudur. Oleh karena itu SDM yang diperlukan adalah:

$\checkmark$ SI-Kimia (MIPA) atau SIFisika (MIPA) atau SIBiologi (MIPA) atau SIGeologi

$\checkmark$ D3-Analis Kimia (MIPA)

$\checkmark$ SMA jurusan IPA

Pertimbangan ini didasarkan bahwa semua sarjana tersebut di atas sudah memiliki pengetahuan dasar ilmu kimia, biologi, dan fisika ketika SLTA serta di awal perkuliahan. Sehingga SDM yang tersedia diharapkan dapat melaksanakan kegiatan analisis laboratorium sebagai pendukung studi teknis konservasi maupun pemugaran.

b) Standardisasi Laboratorium dari Aspek Analisis

Balai Konservasi Peninggalan Borobudur sebagai pusat kajian di bidang konservasi b e r p e r a u n $\mathrm{t} \mathrm{u}$ mengembangkan Analisis Dasar. Analisis dasar tersebut didokumentasikan dalam bentuk Panduan Prosedur Analisis Dasar Laboratorium Konservasi. Prosedur analisis dasar tersebut dapat dilaksanakan dalam setiap kegiatan analisis laboratorium di seluruh BP3. Sebagai konsekuensi Balai konservasi Peninggalan Borobudur juga berperan untuk merencanakan dan melaksanakian program pelatihan analisis dasar. Program pelatihan analisis dasar dapat dilaksanakan dalam bentuk kegiatan Pelatihan Analis Laboratorium Konservasi. Dengan tersedianya Panduan Prosedur Analisis Dasar Laboratorium Konservasi dan program pelatihannya, diharapkan akan terdapat keseragaman dalam prosedur analisis laboratorium di lingkungan Direktorat Peninggalan Purbakala. Sehingga data hasil analisis lebih a k u r t d a $\mathrm{d}$ a $\mathrm{pat}$ dipertanggungjawabkan secara ilmiah.

Panduan analisis dasar tersebut mencakup prosedur analisis, yang memungkinkan dapat dilaksanakan oleh BP3. $\mathrm{Hal}$ ini terkait dengan ketersediaan SDM, alat dan bahan. Sehingga pekerjaan yang $\mathrm{tidak}$ memungkinkan dilaksanakan oleh BP3 karena ketiadaan alat seperti AAS, SEM, UTM, mikroskop binokuler beserta kameranya tidak perlu dilakukan. Prosedur analisis alatalat tersebut dibuat khusus dalam bentuk Dokumen Panduan Mutu Laboratorium. Dokumen Panduan Mutu tersebut sekaligus dipersiapkan sebagai bahan untuk mengajukan akreditasi. Sehingga akreditasi ditujukan hanya pada parameter-parameter uji yang terkait dengan alat-alat tersebut. Pertimbangan ini didasarkan bahwa dokumen panduan mutu bersifat rahasia, artinya tidak boleh diketahui oleh instansi lain.

Adapun jenis-jenis analisis dasar dalam Panduan Prosedur Analisis Dasar Laboratorim Konservasi meliputi:

1) Analisis I:isik/Petrografi Inalisis warna (color chart
- Berat jenis (beker glass, timbangan analitik, oven)

- Kadar air (beker glass, timbangan analitik, oven)

- Porositas (beker glass, timbangan analitik, oven)

- Analisis tekstur

- Analisis struktur

- Analisis kuat tekan pada batu, bata, kayu, dan epoksi resin (compression tester, bor batu)

- Kekerasan (skala mohs)

- Komposisi plester (beaker glass dan timbangan analitik)

- Suhu pembakaran bata dan keramik (muffle furnace, cawan porselin)

2) Analisis biologi

- Analisis visual lumut (loupe)

- Analisis visual algae (handy microscope, camera digital)

- Analisis visual fungi (handy microscope, camera digital)

3) Analisis kimia

- Analisis gravimetri (dalam satuan persen (\%))

Kandungan silica (Si) dan carbonat (CO3) dalam batu, bata (muffle furnice, cawan patina, dan timbangan analitik)

- Analisis titrimetri (dalam satuan persen (\%) atau ppm (part permillion))

Kandungan sulfat (S(O4), clor $(\mathrm{Cl})$, calsium (Ca), alumunium $(\mathrm{Al})$, besi $(\mathrm{Fe})$ dan magnesium ( $\mathrm{Mg}$ ) dalam batu, bata dan plester (micro buret. timbangan analitik. shacker, dan magnetic stirrer)

()leh karena itu semua laboratorium BP3 diharapkan mampu melaksanakan kegratankevitan analisis tersebut di atas 
Balai Konservasi Peninggalan Borobudur selain mengerjakan kegiatan-kegiatan analisis tersebut juga melaksanakan kegiatan analisis khusus meliputi:

1) Analisis SEM (Scaning Electro Microscope, fine coat, dan vacuum evaporation)

- Analisis microstructur (ukuran pori dan butiran pada bata, batu, dan lempung)

2) Analisis Fisik

Analisis fisik yang menggunakan alat UTM antara lain:

- Analisis kuat tekan pada batu, bata, kayu, dan epoksi resin

- Analisis kuat geser tekan pada batu, bata, kayu, dan epoksi resin

- Analisis lentur tarik pada kayu dan epoksi resin

3) Analisis bioassay

- Uji Efektifitas herbisida

- Uji Efektifitas algesida (vertical laminar flow cabinet microscope binokuler dan camera digital khusus)

- Uji Efektifitas fungisida (microscope binoculer, camera digital khusus, lemari pendingin, vertical laminer flow cabinet, autoclave, incubator, oven dll)

- Uji efektifitas insectisida

- Identifikasi spesies jamur

- Identifikasi spesies algae

4) Analisis dengan Alat AAS (Atomic Absorbtion Spectrofotometer)

- Analisis kandungan unsur besi (Fe), timbal (Pb), tembaga ( $\mathrm{Cu})$, crom (Cr), a l um unium (Al), magnesium $(\mathrm{Mg})$, clor (Cl), dan calsium (Ca). c) Standardisasi Laboratorium dari Aspek Status Laboratorium

Laboratorium Balai Konservasi Peninggalan Borobudur merupakan laboratorium konservasi terbesar se-Indonesia dan sudah dikenal sebagai laboratorium konservasi batu se-Asia Tenggara. Oleh karena itu, sudah seharusnya la boratorium B KPB menerapkan Standard ISO/IEC 17025 (ISO: International Organization for Standardisation) untuk menjamin mutu dan keakuratan data hasil pengujian. Penerapan standard ISO tersebut juga sebagai upaya agar data hasil pengujian dapat diakui secara nasional maupun internasional. Sebagai konsekuensi laboratorium BKPB harus mengajukan akreditasi kepada Komite Akreditasi Nasional (KAN). Adapun definisi akreditasi adalah pengakuan formal oleh lembaga yang berwenang (KAN: Komite Akreditasi Nasional) yang menyatakan bahwa suatu laboratorium atau institusi telah memenuhi persyaratan untuk melakukan kegiatan tertentu (pengujian, pemeriksaan, dan kalibrasi).

Persyaratan parameter uji yang diajukan adalah parameter uji yang sering dikerjakan, peralatan yang dipergunakan dikalibrasi secara rutin, SDM yang melaksanakan pengujian sudah berpengalaman. Peralatan yang digunakan sebaiknya merupakan peralatan yang hanya dimiliki oleh BKPB. Hal ini terkait dokumen panduan mutu bersifat rahasia. Beberapa hal yang harus dipersiapkan dalam pengajuan akreditasi antara lain:

1. Sistem Manajemen Mutu dan kompetisi teknis yang memenuhi persyaratan ISO/IEC 17025: 2005 yang didokumentasikan dalam Dokumen Panduan Mutu Laboratorium.

2. SDM yang berkualitas dan memiliki sertifikat:

- Pelatihan Pemahaman ISO $17025: 2005$

- Pelatihan Pembuatan Dokumen Panduan Mutu

- Pelatihan Audit Internal

- Pelatihan Validasi Metode Pengujian

- Pelatihan Kalibrasi Alat

- Pelatihan Estimasi Ketidakpastian Pengukuran

- Pelatihan Jaminan Mutu Pengujian

Pelatihan dapat dilaksanakan s e $n d i r i d e n g a n$ mendatangkan instruktur (konsultan) dari institusi yang berwenang atau mengikutkan staff laboratorium dalam program pelatihan tersebut $\mathrm{di}$ institusi lain seperti: BSN (Badan Standarisari Nasional), dan PT. Embrio Biotekindo.

3. Anggaran biaya yang memadai.

4. Hal mendasar yang harus ada ketika sebuah instansi akan mengajukan akreditasi adalah adanya komitmen yang kuat dari tingkat pimpinan sampai $\mathrm{pada}$ tingkat $\mathrm{staf}$ laboratorium. Akreditasi laboratorium Balai Konservasi Peninggalan Borobudur akan sulit terwujud jika satu saja dari komponen organisasi tersebut tidak memiliki komitmen yang kuat.

5. Adanya Struktur Manajemen I aboratorium sesuai dengan Standard IS( ) $17(1) 25$. 
Struktur Manajemen Laboratorium ini merupakan struktur organisasi bayangan dari struktur organaisasi institusi yang sudah ada. Di mana dalam struktur organisasi ini terdapat manajer puncak, manajer mutu, manajer teknis, manajer administrasi, koordinator mutu internal, koodinator mutu eksternal, TU administrasi, administrasi sampel, penyelia dan analis. Kedudukan manajer administrasi tidak mutlak artinya jabatan manajer administrasi dapat dijadikan satu dengan manajer mutu. Adapun bagan struktur manajemen laboratorium tersebut adalah sebagai berikut:

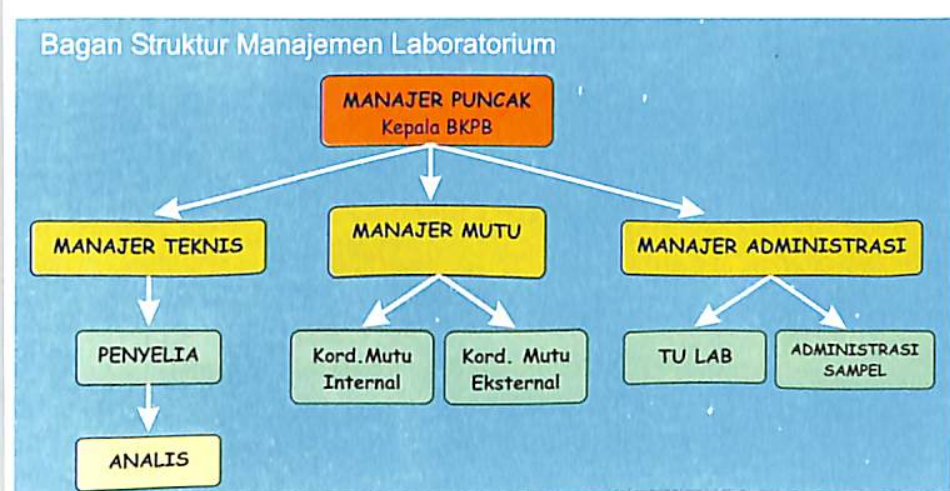

Adapun tugas dari setiap personel dalam struktur managemen labaratorium sebagai berikut:

\section{Manajer puncak}

mengarahkan dan mengendalikan organisasi pada tingkatan tertinggi.

memiliki kewenangan untuk menentukan kebijakan dan sumberdaya baik mutu, teknis dan administrasi yang diperlukan dala m pengoperasian laboratorium sesuai ISO 17025.

memiliki komitmen untuk melaksanakan sistem mutu.

- menetapkan sistem mutu laboratorium sesuai standar ISO 17025.

- menetapkan kaji ulang sistem mutu laboratorium.

- menetapkan susunan personel laboratorium.

Manajer teknis

- bertanggung jawab pada pelaksanaan dan hasil pengujian sampel.

- melaksanakan pengawasan terhadap seluruh kegiatan pengujian.

- melakukan penelusuran hasil pengujian jika ada keluhan teknis dari pelanggan.

- melaksanakan kaji ulang pelaksanaan teknis pengujian.

\section{Manajer mutu}

melaksanakan kaji ulang sistem mutu. - bertanggung jawab d a 1 a $\mathrm{m}$ pelaksanakan audit internal maupun eksternal.

memastikan bahwa pelaksan a n sistem mutu laboratorium sesuai dengan standar ISO 17025.

Manajer administrasi

- bertanggung jawab pada urusan rumah tangga laboratorium.

bertanggung jawab pada pelaksanaan pengadaan bahan, peralatan dan bahan habis pakai.

mengkoordinasikan pengendalian dan distribusi dokumen.

bertanggung jawab dalam penerbitan laporan pengujian.
Penyelia

- membantu manager teknis dalam pengawasan dan pembinaan kegiatan pengujian.

- memeriksa, mengkoreksi dan memaraf hasil pengujian.

Analis

- melakukan pengujian.

- bertanggung jawab terhadap perawatan dan operasional kalibrasi alat.

TU laboratorium

- melaksanakan surat menyurat, pengetikan laporan pengujian.

- melakukan pemilihan, pemesanan dan penyimpanan bahan.

Administrator sampel

- mengelola sampel meliputi, pelabelan, penomoran, dan penyimpanan sampel serta mengisi form instruksi kerja pengujian.

Kordinator mutu internal

- melaksanakan koordinasi pelaksanaan mutu internal seperti kalibrasi alat, validasi dan verifikasi metode.

Kordinator mutu eksternal

- melaksanakan koordinasi pelaksanaan mutu eksternal seperti kalibrasi di luar instansi, penghubung keKAN dan institusi lain.

d) Standardisasi Laboratorium dari Aspek Peralatan

Standardisasi peralatan dilaksanakan dengan cara mengelompokkan peralatan menjadi peralatan primer, peralatan sekunder, dan peralatan tersier Peralatan primer adalah peralatan rang diperlukan untuk kegiatan pengambilan data di lapangan 
Peralatan sekunder merupakan peralatan standar untuk kegiatan analisis di laboratorium. Peralatan primer merupakan peralatan wajib yang harus dimiliki oleh setiap UPT. Peralatan sekunder merupakan peralatan wajib yang harus dimiliki oleh UPT-UPT yang sudah memiliki ruang laboratorium dan ruang penyimpanan bahan kimia. Sehingga UPT-UPT yang belum memiliki ruang laboratorium belum wajib memiliki peralatan sekunder tersebut. Sedangkan peralatan tersier adalah peralatan yang hanya dimiliki BKPB terkait dengan kuantitas penggunaan, SDM, biaya pengadaan, dan servis alat. Pengelompokan peralatan dapat dilihat dalam tabel berikut ini:

\begin{tabular}{|c|c|c|c|}
\hline \multicolumn{2}{|c|}{ Kelompok Alat } & \multicolumn{2}{|r|}{ Nama Alat } \\
\hline A & Primer & $\begin{array}{l}1 \\
2 \\
3 \\
4 \\
5 \\
6 \\
7 \\
8 \\
9 \\
10 \\
11 \\
12 \\
13\end{array}$ & $\begin{array}{ll}1 & \text { skala Mosh (kekerasan) } \\
2 & \text { protimeter } \\
3 & \text { termometer max-min } \\
4 & \text { meteran } \\
5 & \text { termite detector } \\
6 & \text { handy microskop } \\
7 & \text { loupe } \\
3 \text { higrometer } \\
9 \text { termometer } \\
0 \text { luxmeter } \\
1 \text { neopyro } \\
2 \text { camera digital } \\
3 \text { lon meter }\end{array}$ \\
\hline B & Sekunder & $\begin{array}{l}1 \\
2 \\
3 \\
4 \\
5 \\
6 \\
7 \\
8 \\
9 \\
10 \\
11 \\
12 \\
13 \\
14 \\
15 \\
16 \\
17 \\
18 \\
\end{array}$ & $\begin{array}{l}\text { muffle fumice } \\
\text { oven } \\
\text { timbangan analitik } \\
\text { ayakan bertingkat } \\
\text { shacker } \\
\text { alat titrasi } \\
\text { hot plate stimer } \\
\text { pelatatan gelas (glass ware) } \\
\text { cawan patina } \\
\text { lemari asam } \\
\text { lemari pendingin } \\
\text { compression tester } \\
\text { vacuum pump } \\
\text { color chart } \\
\text { jangka sorong } \\
\text { grenda } \\
\text { bor sampel } \\
\text { vicotester }\end{array}$ \\
\hline c & Tersier & $\begin{array}{l}3 \\
4 \\
5 \\
6 \\
7 \\
8\end{array}$ & $\begin{array}{l}\text { AAS } \\
\text { SEM (Scaning Electro Mckroskop, fine coat, vacuum evaporatio) } \\
\text { UTM (Univervesal Testing Machine) } \\
\text { microscop binokuler + camera digital } \\
\text { vertical laminar flow cabinet } \\
\text { autoclave } \\
\text { mikroskop polarisasi + camera digital } \\
\text { ultracut } \\
\text { spektrofotometer }\end{array}$ \\
\hline
\end{tabular}

\section{Penutup}

Terkait dengan tupoksi yang berbeda antara BKPB, BPSMP Sangiran dan BP3 maka sebaiknya dilaksanakan Program Standardisasi Pengelolaan Laboratorium di lingkungan Direktorat Peninggalan Purbakala. Dilaksanakannya program standardisasi dalam pengelolaan laboratorium ini diharapkan dapat meningkatkan peran dan fungsi laboratorium dalam ikut mendukung pelestarian benda cagar budaya di Indonesia. Standardisasi meliputi aspek SDM, analisis, status laboratorium dan peralatan (lihat Tabel. Standarisasi Pengelolaan Laboratorium). Dalam konsep ini belum secara mendalam menyinggung pengelolaan laboratorium BPSMP Sangiran, karena instansi tersebut memiliki materi bcb yang berbeda dengan UPT lain. Oleh karena itu masih sangat diperlukan saran dan masukan untuk menyempurnakannya. 囚

\section{Daftar Istilah}

Standar : ukuran tertentu yang dipakai sebagai patokan

Standardisasi : penyesuaian bentuk (ukuran, kualitas dsb) dengan pedoman (standar) yang ditetapkan

Laboratorium: tempat atau kamar tertentu yang dilengkapi dengan peralatan untuk mengadakan percobaan (penyelidikan)

Penelitian: pemeriksaan yang teliti, penyelidikan kegiatan pengumpulan, pengolahan, analisis, penyajian data yang dilakukan secara sistimatis dan objektif untuk memecahkan suatu persoalan atau menguji hipotesis untuk mengembangkan prinsipprinsip umum
Pengujian : proses, cara, perbuatan menguji

Analisis : penyelidikan terhadap suatu peristiwa untuk mengetahui keadaan yang sebenarnya

Penyelia: pengawas; supervisor

\section{Daftar Pustaka}

Anonim. 2005. Standar Internasional ISO/IEC 17025: Persyaratan Umum Kompetensi Laboratorium Pengujian dan Laboratorium Kalibrasi. Diterjemahkan oleh Komite Akreditasi untuk digunakan sebagai persyaratan akreditasi laboratorium kalibrasi dalam sis te m a kreditasi laboratorium Komite Akreditasi Nasional, Jakarta.

Anonim. 2007. Standarisasi Pengelolaan Laboratorium $\mathrm{d}$ a $\mathrm{l} \mathrm{a} \mathrm{m} \quad \mathrm{R}$ a $\mathrm{n} \mathrm{g} \mathrm{k} \mathrm{a}$ Pengintegrasian Pemanfaatan Laboratorium di Universitas Indonesia. Unit DRPM, Universitas Indonesia, Jakarta.

Anonim. 2008. Kamus Besar Bahasa Indonesia. Pusat Bahasa. Departemen Pendidikan Nasional, Jakarta.

Http.//mbrio-food./article6.htm. Surono, Ir.M.Phil. Peran Laboratorium dalam Pengembangan Mutu dan Keamanan Pangan dan Pertanian. Dikutip tanggal 19 Agustus 2010.

\begin{tabular}{|c|c|c|}
\hline \multicolumn{3}{|c|}{ Tabel. Standardisasi Pengelolaan Laboratorium di Lingkungan Direktorat Purbakala } \\
\hline $\begin{array}{l}\text { Standardisasi } \\
1 \text { Tupoks }\end{array}$ & $\begin{array}{l}\text { BKPB } \\
\text { Melasanacan kajian konservasi, teknik sipil, arsitektur, geologi, biologi, kimia dan arkeologj } \\
\text { Melaksanakan pelathihan analisis laboratorium konservasi }\end{array}$ & $\begin{array}{c}\text { BP3 } \\
\text { Melaksanakan pemeliharaan bcb }\end{array}$ \\
\hline 2 Peran Laboratorium & $\begin{array}{l}\text { Menernukan metode dan bahan konservasi yang tepat sebagai zaven } \\
\text { dalam pelstarian bch }\end{array}$ & $\begin{array}{l}\text { Menentukan atau memilih metode dan bahan konservasi } \\
\text { yang sudah dikaji ideh BKPB }\end{array}$ \\
\hline 3 Sumberdaya Menusia & $\begin{array}{l}\text { 51-Kimia (MPA), S1-Eidogj (MPA), S1-Fisika (MPA), S1-Gedogi, } \\
\text { D3-analis himia (MPA), SMAjurusan IPA }\end{array}$ & $\begin{array}{l}\text { S1-Kmia (MPA) atau S1-Biologi (MPA) atau S1-Fisika (MPA) } \\
\text { atau S1-gedogi dan D3-analis kimia (MPA), SMA jurusan IPA }\end{array}$ \\
\hline 4 Prosedur Analisis & $\begin{array}{l}\text { Panduan Casar Prosedur Analisis Laboratorium } \\
\text { Dokumen Panduan Mutu Laboratorium }\end{array}$ & Panduan Dasar Prosedur Analisis Laboratorium \\
\hline 5 Status laboratorium & Terakreditasi & Tidak terakreditasi \\
\hline 6 Peralatan & $\begin{array}{l}\text { Primer } \\
\text { Sekunder } \\
\text { Tersier }\end{array}$ & $\begin{array}{l}\text { Primer } \\
\text { Sekunder }\end{array}$ \\
\hline
\end{tabular}

